\title{
AS CONTRIBUIÇÕES DAS ESTRATÉGIAS DE LEITURA PARA A COMPREENSÃO DE UM LIVRO ILUSTRADO
}

\author{
Andreia Santos Oliveira ${ }^{1}$ \\ Dhttps://orcid.org/0000-0003-4623-9757 \\ Daniele Aparecida Russo ${ }^{2}$ \\ Dhttps://orcid.org/0000-0001-8154-6192 \\ Cyntia Graziella Guizelim Simões Girotto 3 \\ Dhttps://orcid.org/0000-0003-0620-4613
}

Resumo: Diante da importância da formação do leitor, pretendemos apresentar neste artigo uma proposta prática do uso das estratégias de leitura para a compreensão do livro ilustrado $A$ vaca que botou um ovo (CUTBILL; 2010). Trata-se de um recorte de pesquisa de doutorado, cujo objetivo foi investigar o papel dos outros "mediadores de leitura" na formação do leitor literário, desenvolvida para seis alunos do 5o ano do Ensino Fundamental de uma escola municipal de Porto Velho/RO em junho de 2019. A dialogia fundamentada pela filosofia da linguagem (BAKHTIN, 2003; VOLOCHINOV, 2017) foi a escolha metodológica para a atividade em foco com o propósito de apresentar possibilidades de práticas pedagógicas para a formação do leitor literário. Os resultados demonstram a importância de criar condições favoráveis para que as crianças tenham acesso ao texto literário bem como desenvolvam condutas necessárias ao ato de ler, dentre elas destacamos o uso das estratégias de leitura.

Palavras-chave: Formação do leitor. Estratégias de leitura. Literatura infantil. Livro ilustrado.

\footnotetext{
1 Doutoranda em Educação pela Universidade Estadual Paulista "Júlio de Mesquita Filho", campus Marília. Mestra em Educação, pós-graduada em Linguística Aplicada ao Ensino de Língua e Literatura, Licenciada em Letras. Professora de Língua Portuguesa e Literatura do Instituto Federal de Rondônia. E-mail: andreia.oliveira@ifro.edu.br

2 Doutoranda em Educação pela Universidade Estadual Paulista Julio de Mesquita Filho, Campus Marília. E-mail: danirusso1@hotmail.com

3 Livre-docente em Leitura e Escrita pela Universidade Estadual Paulista (2016). Pós-doutorado em Leitura e Literatura Infantil pela Universidade de Passo Fundo (2015). Doutora em Educação pela Unesp (1999). Mestre em Educação pela Universidade Federal de São Carlos (1995). Pedagoga pela Faculdade de Filosofia e Ciências - Unesp - Marília (1992).E-mail: cyntiaunespmarilia@gmail.com
} 


\title{
THE CONTRIBUTIONS OF READING STRATEGIES TO UNDERSTAND NA ILLUSTRADED BOOK
}

\begin{abstract}
Given the importance of reader training, we intend to present in this article a practical proposal for the use of reading strategies to understand the illustrated book $A$ vaca que botou um ovo (CUTBILL; 2010). The activity reported is a clipping of doctoral research whose objective is to investigate the role of the other "reading mediators" in the formation of the literary reader and was developed for six students in the 5th year of elementary school at a municipal school in Porto Velho / RO in June 2019. The dialogue based on the philosophy of language (BAKHTIN, 2003; VOLOCHINOV, 2017) was the methodological choice for this class, whose objective is to present possibilities of pedagogical practices for the formation of the literary reader. The results demonstrate the importance of creating conditions for children to have access to the literary text as well as to develop the necessary behaviors for the act of reading, among which we highlight the use of reading strategies.
\end{abstract}

Keywords: Reader training. Reading strategies. Children's literature. Picture book.

\section{LAS CONTRIBUCIONES DE LAS ESTRATEGIAS DE LECTURA PARA COMPRENDER UN LIBRO ILUSTRADO}

Resumen: Dada la importancia de la formación del lector, pretendemos presentar en este artículo una propuesta práctica para el uso de estrategias de lectura para la comprensión del libro ilustrado La vaca que puso un huevo (CUTBILL; 2010). La actividad reportada es un recorte de la investigación doctoral cuyo objetivo es indagar en el papel de los otros "mediadores de la lectura" en la formación del lector literario y fue desarrollada para seis estudiantes de 5o año de primaria en una escuela municipal de Porto Velho. / RO en junio de 2019. El diálogo basado en la filosofía del lenguaje (BAKHTIN, 2003; VOLOCHINOV, 2017) fue la elección metodológica para esta clase, cuyo objetivo es presentar posibilidades de prácticas pedagógicas para la formación del lector literario. Los resultados demuestran la importancia de crear condiciones para que los niños tengan acceso al texto literario así como para desarrollar las conductas necesarias para el acto de leer, entre las que destacamos el uso de estrategias lectoras.

Palabras clave: Formación del lector. Estrategias de lectura. Literatura infantil. Libro de fotos.

\section{Introdução}

Leitura é a atividade estreitamente ligada à totalidade do sujeito, ao que ele é, ao que ele vive e a seu projeto atual. "Ler é ter escolhido procurar alguma coisa; dissociada dessa intenção, a leitura não existe. Já que ler é encontrar a informação que escolhemos, a leitura é por natureza flexível, multiforme, sempre adaptada à pesquisa", argumenta Foucambert (2008, p. 64). 
A partir dessa concepção de leitura, consideramos que ensinar o ato cultural de ler envolve o ensino dos modos de dialogar com os textos para a construção de sentidos. Dentre esses, destacamos a importância de mobilizar estratégias de leitura para a formação do leitor. Com foco na formação do leitor literário e a partir da concepção de leitura apresentada acima, os professores podem contribuir para criar nas crianças a necessidade estética de ler e colocá-las em contato direto com os livros, a saber de literatura infantil, dentre eles os ilustrados.

Assim, pretendemos neste texto apresentar uma proposta prática com as estratégias de leitura a partir do livro ilustrado de literatura infantil intitulado $A$ vaca que botou um ovo. A obra foi publicada originalmente em inglês em 2007. Escrita por Andy Cutbill e ilustrada por Russell Ayto, foi traduzida para o português por Lenice Bueno e publicada em 2010 pela editora Salamandra. Diante da qualidade estética literária e gráfico editorial da obra, foi escolhida para a atividade de leitura com alunos do Ensino Fundamental.

A aula de leitura aconteceu em junho 2019, com seis crianças do 5o ano do Ensino Fundamental de uma escola municipal de Porto Velho, Rondônia.

A metodologia dialógica fundamentada pela filosofia da linguagem (BAKHTIN, 2003; VOLOCHINOV, 2017) norteou a investigação. O diálogo, portanto, foi essencial, pois "quando estudamos o homem, procuramos e encontramos signos em toda sua parte e nos empenhamos em interpretar o seu significado" (BAKHTIN, 2003, p. 319). Nesta perspectiva, o pesquisador faz parte do diálogo e considera os enunciados dos sujeitos participantes da pesquisa como objeto de investigação. As escolhas teóricas e metodológicas assumidas com base na dialogia auxiliaram na geração, organização, análise e compreensão dos dados em consonância com os princípios da pesquisa em Ciências Humanas com sujeitos expressivos e falantes em realidades singulares.

Com objetivo de apresentar possibilidades de práticas pedagógicas para a formação do leitor literário, abordarmos na análise da obra A vaca que botou um ovo conceitos sobre livro ilustrado (LINDEN, 2011), inclusive sobre os paratextos; e utilizamos as estratégias de leitura (GIROTTO; SOUZA, 2010) para atribuição de sentidos à obra. As estratégias utilizadas na aula de leitura e aqui apresentadas são as 
de ativar conhecimentos prévios, bem como a visualização, as conexões, os questionamentos e a inferência.

\section{Análise da obra A vaca que botou um ovo}

A obra $A$ vaca que botou um ovo narra a história de Mimosa (Mimi), uma vaca que se sentia deprimida em virtude de não se sentir especial em relação às demais da fazenda onde vivia. Enquanto suas colegas praticavam ações, em sua concepção especiais, como andar de bicicleta, plantar bananeira e fazer estrela, Mimi não possuía essas habilidades. Vendo a angústia pela qual passava o animal, as galinhas quiseram saber o motivo e Mimi explicou a elas.

A partir desse momento tem início a complicação da história. As aves arquitetam um plano e, no dia seguinte, toda a fazenda acorda ao som estridente de Mimi gritando que havia botado um ovo. Este fato gera inveja nas demais vacas. Inconformadas por perderem o status de especiais, começam a duvidar de que Mimosa de fato tenha botado um ovo e a questionam, acusando-a de juntamente com as galinhas ter arquitetado um plano. Entretanto, diante da negativa das galinhas, as demais vacas passam a esperar o momento em que o ovo seria chocado e daria vida a um novo ser, pois apenas desse modo poderiam provar a sua tese.

O tempo transcorre e um dia nasce dele uma "bolinha de penas". As vacas ficam felizes por pensarem ter provado o plano arquitetado, contudo, o desfecho é surpreendente. A pequena ave em vez de cacarejar, como é típico das galinhas, muge fazendo com que Mimosa fique extremamente feliz com a chegada de sua filha nomeada por ela de Daisy.

Sophie Van der Linden em sua obra Para ler o Livro ilustrado tece considerações a respeito da composição de livros dedicados ao público infantil. Como a imagem é muito presente nesses gêneros textuais, ela propõe uma diferenciação entre livros ilustrados e livros com ilustrações. Ao aplicar os conceitos produzidos por Linden (2011) na obra em análise, podemos classificá-la como livro ilustrado, tendo em vista que 
[...] o livro ilustrado evoca duas linguagens: o texto e a imagem. Quando as imagens propõem uma significação articulada com a do texto, ou seja, não são redundantes à narrativa, a leitura do livro ilustrado solicita apreensão conjunta daquilo que está escrito e daquilo que é mostrado. (LINDEN, 2011, p. 8).

Para atribuir sentido à obra, aqui em análise, o leitor precisa estar atento às duas formas de linguagem, pois uma complementa o sentido da outra. Ou ainda remonta a uma terceira narrativa.

Linden (2011, p. 8) defende que a leitura do livro ilustrado não é tarefa simples. Pelo contrário, mesmo sendo constituído de imagens “[...], cujo alcance é sem dúvida universal, não exigem menos do ato de leitura [...] assim como o texto, a imagem requer atenção, conhecimento de seus respectivos códigos e uma verdadeira interpretação". É preciso muita atenção do leitor para ler cada uma das imagens presentes nas 15 páginas do livro em análise. Todas elas, com exceção da última página, são duplas; e texto e imagem são distribuídos em um espaço de 26 centímetros de altura e 52, de largura.

A vaca que botou um ovo é um livro em que há a presença de cores fortes. Ao passar das páginas, mudam-se também as cores escolhidas como pano de fundo. Cores fortes como o verde, amarelo, azul, preto, lilás, rosa e amarelo compõem a formatação do livro. A maioria das cores usadas remetem a alguns dos elementos do cenário de uma fazenda: o verde da grama, o laranja de um dia ensolarado, o azul do céu e o preto da noite (momento em que as galinhas arquitetaram o plano para ajudar a amiga Mimi). 0 rosa está presente em três momentos da narrativa: para destacar o local ocupado pela mulher do fazendeiro no momento em que ela liga para o jornal da cidade a fim de avisar o fato extraordinário: sua vaca havia botado um ovo; na página dupla em que as vacas acusam Mimosa de não ser a dona do ovo; e na última página, momento em que Mimosa embala sua filha nos braços e a nomeia de Daisy. Por esses fatos, a cor rosa pode estar relacionada à questão da feminilidade.

A atribuição de sentido à obra já tem início logo na capa com o título antecipador do personagem protagonista e a ação praticada por ele. Ao ler o título, o leitor percebe que encontrará um fato inusitado dentro do texto. A partir dele, a curiosidade é aguçada para descobrir o que desencadeou tal consequência. 0 título 
em letras brilhantes azuis está localizado no lado esquerda da página e contrasta com o fundo rosa da página. Na parte inferior há os nomes do autor, ilustrador e editora, todos escritos em letra maiúscula na cor branca. Localizada ao lado direito está a imagem de uma vaca com semblante triste e a imagem escavada em forma de um ovo pintado com bolinhas pretas. A cor do ovo fica por conta da guarda inicial: uma página em branco com vários círculos pretos remetendo à figura da vaca pintada. Nas guardas seguintes, em uma das páginas prossegue a imagem que lembra a vaca pintada e, na outra, há a presença de três galinhas caminhando em fila indiana.

$\mathrm{Na}$ quarta página além de um pequeno resumo da narrativa há a imagem de três vacas executando ações extraordinárias: enquanto uma anda de bicicleta, as outras duas fazem estrela e plantam bananeira. Ao fundo, aparece Mimosa com expressões tristes, com uma nuvem negra sobre sua cabeça e as três galinhas. Pela disposição, é possível inferir que estão dialogando. Todos esses elementos são importantes para a atribuição de sentido ao texto como orienta Linden (2011, p. 8-9): "Ler um livro ilustrado é também apreciar o uso de um formato, de enquadramentos, da relação entre capa e guardas com seu conteúdo [...]. Ler um livro ilustrado depende certamente da formação do leitor".

Sabendo da importância da leitura de todos esses elementos citados acima para a atribuição de sentido ao texto, faz-se necessário apresentá-las aos alunos para que desde os anos iniciais possam compreender os modos de leitura do livro ilustrado de literatura infantil.

\section{A utilização das estratégias de leitura para atribuição de sentido à obra}

Para a aula de leitura em que trabalhamos com as estratégias de leitura, apoiamo-nos nas orientações de Girotto e Souza (2010), mais especificamente em um capítulo escrito pelas autoras no livro Ler e compreender: estratégias de leitura.

Se ler não é decodificar mas atribuir sentido ao texto, devemos compreender a leitura como questão de estratégia ou como disse Jolibert e Jacob (2006) uma questão de interrogar o texto que está sendo lido. Os leitores experientes fazem isso de forma autônoma e até automática. Ao se deparar com determinado gênero textual acionam as estratégias de leitura e elaboram questionamentos que ajudarão na atribuição de 
sentido. Entretanto, essa é uma habilidade que deve ser aprendida. Não nascemos leitores, formamo-nos no contato com os textos por meio da mediação de um adulto mais experiente. Logo, se para ler necessitamos usar as estratégias de leitura, elas precisam ser ensinadas aos pequenos leitores em processo de formação.

Girotto e Souza (2010) enumeram em sete as estratégias metacognitivas de leitura. São elas: conhecimentos prévios, conexões, inferências, visualização, perguntas ao texto, sumarização e síntese. Neste artigo nos deteremos em apenas cinco delas, pois foram as utilizadas na aula de leitura com alunos do quinto ano do Ensino Fundamental.

Iniciamos a aula informando às crianças que faríamos a transmissão vocal de uma obra literária, cujo personagem principal seria uma vaca e solicitamos a elas a enumeração de conhecimentos já tidos em relação a esse animal. 0 termo transmissão vocal é utilizado por Bajard (2014) e segundo este autor não podemos confundi-lo com o verbo ler. Temos essa modalidade de acesso à narrativa no momento em que "[...] o texto passa do livro à voz" (BAJARD, 2014, p. 64). Escolhemos essa forma de apresentar a obra aos alunos porque havia apenas um livro à disposição e também queríamos mostrar a elas como a utilização das estratégias de leitura podem contribuir para a atribuição de sentidos ao texto.

As crianças demonstraram ter conhecimentos prévios em relação ao personagem principal da obra. Isso é fundamental na atribuição de sentidos, diz Foucambert (1994, p. 8, grifos do autor), visto que "A leitura é a atribuição de um significado ao texto escrito: $20 \%$ de transformações visuais, provenientes do texto; 80\% de informações que provêm do leitor; o resto é informação sonora [...]". Alguns dos conhecimentos prévios demonstrados pelas crianças em relação ao animal vaca foram: produz leite, tem filhotes, é um mamífero, come grama e mora em uma fazenda. Ao fazer isso, mostramos às crianças a importância de mobilizar os conhecimentos prévios, pois esta estratégia é fundamental para a atribuição de sentido. De acordo com Girotto e Souza (2010, p. 50): "Antes de ler, bons leitores ativam conhecimentos prévios que podem então estar relacionados às ideias do texto". Ainda de acordo com essas professoras pesquisadoras: "O conhecimento prévio é considerado por vários autores como a estratégia "guarda-chuva" (GIROTTO; SOUZA, 2014, p. 15), pois 
durante todo o ato de ler, os leitores utilizam seus conhecimentos prévios e os relacionam com o que está sendo lido. Assim como Kleiman (1989), Girotto e Souza (2014), defendem que aqueles conhecimentos prévios trazidos pelas crianças para suas leituras fornecem subsídios para aprendizagem e compreensão textual.

Após esse momento inicial, informamos aos alunos o título da obra e pedimos que a partir dele fizessem inferências a respeito da história que seria narrada. Como na atividade anterior, as crianças haviam dito que vaca é mamífero, elas ficaram intrigadas com a possibilidade do animal botar um ovo, o que demonstra a importância dos conhecimentos prévios para a compreensão textual. Como o título explicita bem o fato narrado, todos inferiram adequadamente: a história seria de uma vaca que botou um ovo. A dúvida era: como? Por quê? Será? Em seguida, apresentamos o nome do autor, ilustrador e editora e questionamos se já haviam lido outros produzidos por eles, mas todos desconheciam tanto autor quanto ilustrador.

Até o momento não havíamos mostrado às crianças o livro e isso foi intencional, pois almejávamos trabalhar com a estratégia de leitura denominada visualização. Girotto e Souza (2010, p. 85) compreendem a visualização como momento de "[...] inferir significados, por isso visualização é uma forma de inferência, justificando a razão dessas duas estratégias, serem abordadas tão proximamente". As autoras orientam ainda que essa estratégia pode ser mobilizada em três momentos: antes, durante e após o ato de ler e para visualizar usamos os conhecimentos que já trazemos a respeito do texto, bem como passagens ricas em detalhes. Como todas as outras, essa estratégia deve ser ensinada e para isso:

[...] é importante escolher uma leitura vívida, para modelar as imagens que fazemos individualmente. Livros com gravuras, com rica linguagem descritiva e verbos ativos são recursos tão bons quanto alguns bons livros escritos em capítulos (DAVIS; SOUZA, 2009, p. 35).

Sendo assim, por considerar o título da história rico em detalhes, solicitamos a ilustração do que as crianças acreditavam encontrar, na sequência, na história. Abaixo apresentamos as ilustrações produzidas: 
Imagem 1 - Ilustração produzida por Nina ${ }^{4}$

Imagem 2 - Ilustração produzida por

Valentina

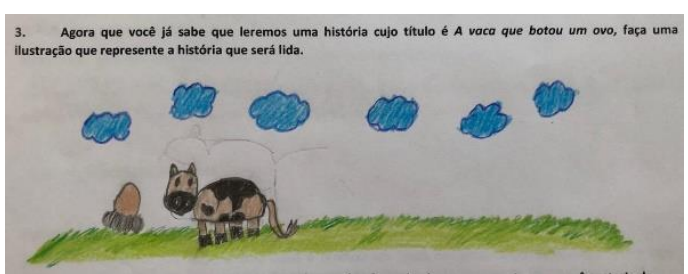

Fonte: Acervo das autoras (2019).

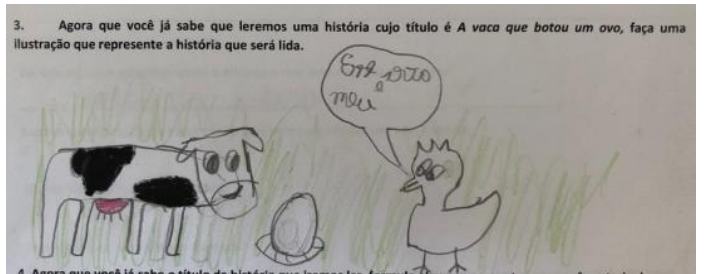

Fonte: Acervo das autoras (2019).

Imagem 3 - Ilustração produzida por Emília Imagem 4 - Ilustração produzida por Eveline

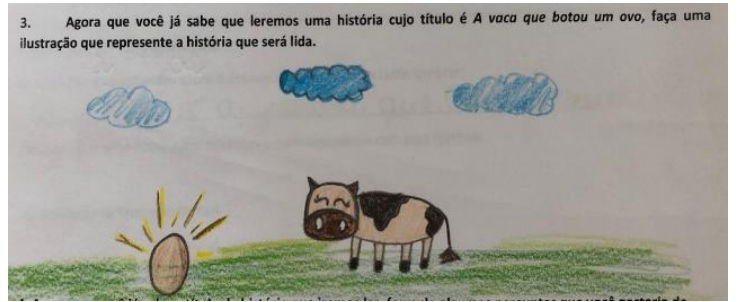

Fonte: Acervo das autoras (2019).

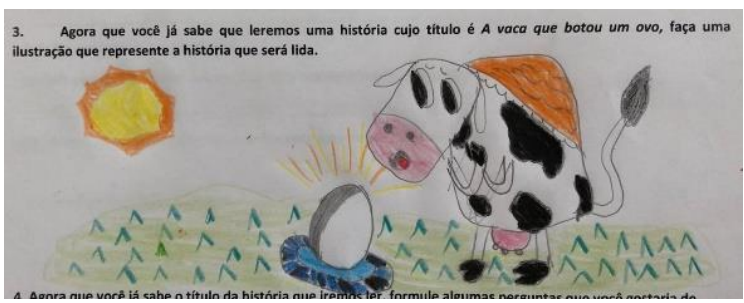

Fonte: Acervo das autoras (2019).

Imagem 5 - Ilustração produzida por Mônica

Imagem 6 - Ilustração produzida por Nikolai

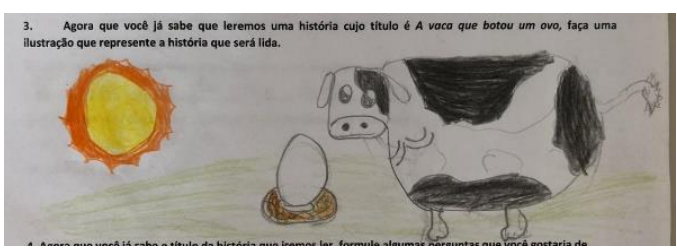

Fonte: Acervo das autoras (2019).

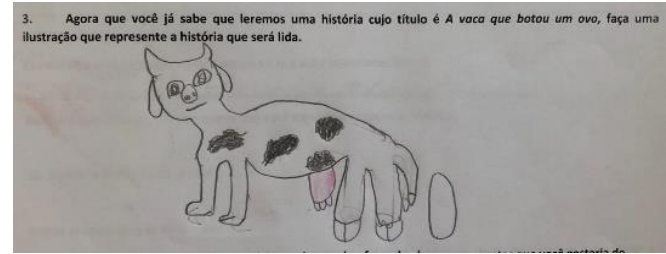

Fonte: Acervo das autoras (2019).

As ilustrações demonstram que as crianças seguiram fielmente a mensagem passada pelo título da obra. Destaque há para a evidência de que todas as ilustrações remetem à figura de uma vaca malhada olhando para um ovo à sua frente, exceto Nikolai que desenhou o ovo atrás da vaca. Essa foi uma inferência feita pelas crianças que se comprovou logo que o livro foi apresentado, pois, na capa, Mimosa, a vaca malhada, observa um ovo bem à sua frente. Entretanto, enquanto as crianças

\footnotetext{
${ }^{4}$ Para manter o anonimato das crianças, usamos nomes fictícios para todas elas.
} 
desenharam ovos brancos ou marrons, no livro, o ovo é malhado. Acreditamos que o desenho das crianças se deva aos seus conhecimentos prévios a respeito das características ovo. Das sete crianças, apenas Valentina demonstrou por meio da ilustração ter inferido que o ovo não foi botado pela vaca, mas por uma galinha. A aluna inferiu também que o ovo possa ter sido roubado por Mimosa. Várias inferências realizadas foram comprovadas na escuta do texto o que demonstra que de fato na atribuição de sentido estão envolvidas várias estratégias.

Destacamos que as crianças não estavam realizando a leitura silenciosa da obra, mas ouvindo e visualizando as ilustrações presentes no livro. Entretanto, criamos condições para o uso das estratégias de leitura, na intenção de que compreendessem como deveriam se comportar diante de um livro ilustrado no momento em que fossem lê-lo e que isso sempre passa pela elaboração de inferências, pois "Ler - e, portanto, aprender a ler - é uma negociação entre o conhecido, que está na nossa cabeça, e o desconhecido, que está no papel; entre o que está atrás e o que está diante dos olhos" (FOUCAMBERT, 1994, p. 38).

A partir disso, prosseguimos com as atividades, cujos objetivos específicos eram o de mobilizar os conhecimentos prévios e fazer mais inferências. Para isso, apresentamos a quarta capa às crianças e solicitamos que fizessem a leitura das imagens presentes. Como há a presença de vacas andando de bicicletas, fazendo estrela e plantando bananeira, perguntamos às crianças se conheciam essas brincadeiras. Diante da resposta positiva, alguns sentiram necessidade de relatar momentos em que também brincaram dessa forma, realizando a conexão texto-leitor. Girotto e Souza (2010, p. 67) explicam que "Os leitores fazem naturalmente conexões entre os livros e fatos de sua vida". Isto é, aproveitam as suas experiências pessoais para a construção de sentidos dos textos (GIROTTO; SOUZA, 2010).

As crianças também destacaram a presença da vaca Mimosa e pelas leituras das imagens concluíram que ela estava triste e conversava com as galinhas, suas amigas. Feito isso, fizemos a transmissão vocal do pequeno resumo presente na quarta capa e, como nele informa, "Num belo dia, Mimosa descobrirá algo especial" (CUTBILL, 2010, quarta capa), questionamos as crianças sobre as inferências que 
faziam para esse algo especial. Todas foram unanimes e inferiam que seria o fato da vaca botar ovo.

A inferência “[...] é fundamental na compreensão" (GIROTTO, SOUZA, 2010, p. 76). Trata-se da ação de supor algo a respeito do texto com base nas informações já obtidas. Solé (1998) nomeia esse ato de estabelecer previsões sobre o texto. Independente da nomenclatura, o importante é saber que ativar essa estratégia contribui para a atribuição de sentido ao texto, tanto que Rabikin (1973 apud HUNT, 2010) e Kleiman (1989) definem a leitura como sendo ato de elaborar hipóteses e testá-las.

Em um livro ilustrado como é o caso de $A$ vaca que botou um ovo, podemos utilizar os elementos paratextuais como capa, quarta capa e guardas para motivar as crianças a externalizarem os seus conhecimentos prévios e fazerem inferências. Tanto que no momento em que viram as galinhas na imagem da quarta capa, muitos inferiram que o ovo não seria de Mimosa, mas das aves. Inferência fortalecida no momento em que as crianças viram em uma das guardas, três galinhas caminhando em fila.

Ainda antes de iniciar a transmissão vocal do texto, solicitamos que as crianças preenchessem a primeira lacuna do quadro abaixo. A atividade foi baseada na sugestão de Girotto e Souza (2010).

Quadro 1 - Folha do pensar/ Cartaz para inferência

\begin{tabular}{|l|l|l|}
\hline Palavra & $\begin{array}{l}\text { Significado Inferido antes da } \\
\text { escuta do texto }\end{array}$ & $\begin{array}{l}\text { Significado inferido após a escuta } \\
\text { do texto }\end{array}$ \\
\hline Deprimida & & \\
\hline Cacarejar & & \\
\hline Arquiteratam & & \\
\hline Agitação & & \\
\hline Curral & & \\
\hline
\end{tabular}




\section{Estridente}

Fonte: As autoras (2019)

Todos os alunos completaram a primeira coluna, conforme apresentamos abaixo:

Emília: deprimida: é uma pessoa triste. Cacarejar: um galo a cantar. Agitação: coisas rápidas. Curral: onde as vacas ficam. Estridente: grito alto.

Nina: deprimida: uma pessoa que se sente triste. Cacarejar: um galo a cantar. Agitação: uma pessoa feliz, animada. Curral: onde ficam as vacas e outros animais. Estridente: grito alto.

Valentina: deprimida: triste. Cacarejar: tipo de gritar. Agitação: alegria. Curral: lugar grande. Estridente: não sei.

Eveline: Deprimida: é quando estou triste. Cacarejar: mooooo. Arquiteram: um plano. Agitação: é quando ela está com raiva. Curral: um lugar aberto. Estridente: grito alto.

Mônica: Deprimida: Quando a vaca não está deprimida. Cacarejar: mooo. Arquiteram: um plano. Agitação: quando ela quer proteger seus filhos. Curral: um lugar deserto. Estridente: grito alto.

A palavra que as crianças mais encontraram dificuldades para inferir o sentido foi o verbo arquitetaram. Tanto que apenas Eveline e Mônica deram um sentido a ele antes da escuta do texto. Os demais deixaram sem respostas. A palavra cacarejar também causou confusão de sentidos como pode ser visto nas respostas de Eveline e Mônica. Como as crianças moram em uma cidade relativamente grande, capital do estado, também tiveram dificuldade para dizer com precisão o sentido da palavra curral, possivelmente por desconhecerem este espaço comum para os moradores da zona rural. De tudo isso, denota-se a dificuldade das crianças em atribuir sentido a palavras isoladas, mesmo que sejam relativamente simples. 
Após a escuta do texto, as crianças voltaram a completar o quadro com os sentidos construídos pelo contexto no qual a palavra estava sendo usada. Neste momento, nenhuma criança teve dificuldade em atribuir sentido a nenhum vocábulo o que demonstra que "A palavra na vida, com toda evidência, não se centra em si mesma. Surge da situação extraverbal da vida e conserva com ela o vínculo mais estreito. E mais, a vida completa diretamente a palavra, que não pode ser separada da vida sem que perca seu sentido" (VOLOCHÍNOV, 2013, p. 77).

Sabendo que ler é uma questão de interrogar o texto como defende Jolibert e Jacob (2006), após apresentar o título, as guardas e quarta capa, solicitamos das crianças a elaboração de algumas perguntas cujas respostas elas gostariam de encontrar durante a escuta da história. Essa foi a atividade que as crianças mais demonstraram dificuldades. Inicialmente não conseguiram elaborar nenhuma indagação. Talvez isso tenha ocorrido pelo fato de como a leitura é trabalhada em sala de aula. Geralmente os alunos leem o texto e, após esse momento, respondem questões propostas pelo professor ou pelo livro didático. Entretanto, mais do que responder perguntas elaboradas por terceiros, o próprio leitor é quem deve fazê-las. Argumenta Arena (2015, p. 139-140).

[...] é possível destacar que, ao longo da história do ensino da leitura, o aluno devia entender que saber ler seria saber responder a perguntas do outro, mas a prática cultural e social do ato de ler revela que, na essência, que o leitor não responde senão a suas próprias perguntas movimento que o faz avançar pelas páginas de um livro e que o coloca em patamar mais acima em sua própria evolução intelectual.

Quando as questionamos se já haviam feito atividade parecida com essa, responderam negativamente. Diante da dificuldade, foi preciso contribuir com orientações mais específicas: Gente, o título é A vaca que botou um ovo. Vaca bota ovo? Então que pergunta eu poderia fazer? A partir dessa orientação, os alunos fizeram esses questionamentos a partir do título:

Eveline: Como a vaca coloca um ovo? O que vai ter na história? 
Nina: Como a vaca botou um ovo? O ovo é branco e com manchas?

Emília: Como que uma vaca bota um ovo?

Mônica: Como uma vaca pode colocar ovos?

Nikolai: Como a vaca bota ovo? Por que ela está triste? (junho de 2019).

Percebemos que as indagações giraram em torno do fato excepcional de uma vaca botar um ovo. Apenas Nina demonstrou curiosidade em relação a cor do ovo, pois isso poderia fornecer indícios sobre a sua origem. Nikolai além de querer saber da possibilidade de uma vaca botar ovo, demonstrou curiosidade sobre o motivo de sua tristeza.

Questionar o texto é uma importante estratégia que pode ser suscitada durante o ato de leitura (SOLÉ, 1998; GIROTTO; SOUZA, 2010). Trata-se de questionar o que está sendo lido, mais do que responder, como é feito nas aulas de leitura tradicionais, essa estratégia requer que o leitor elabore indagações ao escrito. Solé justifica a importância dessa estratégia ao afirmar: "No entanto, alguém que assume a responsabilidade em seu processo de aprendizagem é alguém que não se limita a responder às perguntas feitas, mas que também pode interrogar e auto-interrogar-se" (SOLÉ, 1998, p.110).

O questionamento é uma estratégia que pode ser desenvolvida durante toda a leitura. Por isso, à medida que transmitíamos o texto, perguntávamos se as crianças tinham novas perguntas para fazer. Percebemos que as crianças haviam entendido a proposta e estavam mais aptas a fazer novas indagações que no momento inicial. Alguns questionamentos feitos durante a leitura foram: Será que as vacas vão conseguir provar que Mimosa não botou o ovo? O que será que vai nascer do ovo? (MÔNICA, junho de 2019). Será que as galinhas vão conseguir provar (EMÍLIA, junho de 2019). Que vai nascer: um pintinho ou uma vaca? (NINA, junho de 2019). Foi a vaca que botou um ovo? (VALENTINA, junho, 2019). O que vai nascer? (EVELINE, junho de 2019). O questionamento, portanto, permeou toda a atividade acerca do livro ilustrado. 
Por fim, exemplificar a prática do trabalho em sala de aula com as estratégias de leitura a partir do livro ilustrado de literatura infantil, focalizando a formação do leitor, foi o nosso propósito. É importante salientar que o professor pode organizar o ensino das estratégias de leitura a partir de vários outros livros de literatura infantil, além de explorar as demais estratégias de compreensão leitora.

\section{Conclusão}

O leitor é capaz de atribuir sentidos ao texto a partir de um complexo exercício cognitivo quando lê. E, nesse movimento ativo, o leitor dialoga com a narrativa escrita e visual, relaciona ideias do livro com seus conhecimentos prévios, constrói imagens mentais, provoca sumarizações, ou seja, mobiliza várias estratégias de leitura quando lê. Portanto, a atribuição consciente de sentidos ao texto faz parte do movimento de formar o leitor autônomo e experiente.

Consciente desse movimento, o professor é responsável por organizar seu trabalho pedagógico para formar leitores pelos caminhos do uso das estratégias de leitura a partir da literatura infantil, inclusive, como demonstramos durante o texto, do livro ilustrado $A$ vaca que botou um ovo.

A partir da mobilização das estratégias de compreensão leitora, as crianças atribuiram sentido ao texto e às imagens em dialogia com eles; e compreenderam os modos de ler o livro ilustrado. O que foi possível confirmar a partir dos seus enunciados orais e nos desenhos, ressaltando o trabalho com as estratégias de leitura como importante à medida que permite ao leitor ampliar e modificar os processos mentais de conhecimento para melhor compreender o texto e o mundo em que vive.

\section{Referências}

ARENA, Dagoberto Buim. Para ensinar a ler: práticas e tendências. In: MIGUEL, José Carlos; REIS, Martha. Formação docente: perspectivas teóricas e práticas pedagógicas. Marília: Oficina Universitária; São Paulo: Cultura Acadêmica, 2015. p. 135-154.

BAJARD, Elie. Ler e dizer: compreensão do texto escrito. São Paulo: Cortez, 2014.

BAKHTIN, Mikhail. Estética da criação verbal. Tradução Paulo Bezerra. 4. ed. São Paulo: Martins Fontes, 2003. 
CUTBILL, Andy. A vaca que botou um ovo. Tradução Lenice Bueno. Ilustração Russel Ayto. São Paulo: Salamandra, 2010.

DAVIS, C. Lynn; SOUZA, Renata Junqueira. Entendendo textos: estratégia para a sala de aula. Leitura: Teorias e Prática, Campinas, v. 27, n. 53, p. 31-37, 2009.

FOUCAMBERT, Jean. A leitura em questão. Tradução Bruno Charles Magne. Porto Alegre: Artmed, 1994.

FOUCAMBET, Jean. Modos de ser leitor: aprendizagem e ensino da leitura no ensino fundamental. Curitiba: Editora UFPR, 2008.

GIROTTO, Cyntia Graziella Guizelim Simões; SOUZA, Renata Junqueira. Estratégias de leitura: para ensinar alunos a compreender o que leem. In: GIROTTO, Cyntia Graziella et. al. (org.). Ler e compreender: estratégias de leitura. Campinas: Mercado das Letras, 2010. p. 45-114.

GIROTTO, Cyntia Graziella Guizelim Simões; SOUZA, Renata Junqueira. Estratégias de leitura: uma alternativa para o início da educação literária. Álabe, Almeria, n. 10, p. 123, dez. 2014.

HUNT, Peter. Crítica, teoria e literatura infantil. Tradução Cid Knipel. São Paulo: Cosac Naify, 2010.

JOLIBET, Josette; JACOB, Jeannette e colaboradores. Além dos muros da escola: a escrita como ponte entre alunos e comunidade. Tradução Ana Maria Netto Machado. Porto Alegre: Artmed, 2006.

KLEIMAN, Angela. Texto e leitor: aspectos cognitivos da leitura. Campinas: Pontes, 1989.

LINDEN, Sophie Van der. Para ler o livro ilustrado. Tradução Dorothé de Bruchard. São Paulo: Sesi, 2011.

SOLÉ, Isabel. Estratégias de leitura. Tradução Cesar Coll. 6. ed. Porto Alegre: Artmed, 1998.

VOLOCHÍNOV, Valentin. A construção do enunciado e outros ensaios. Tradução João Wanderley Geradi, Valdemir Miotello. São Carlos: Pedro \& João editores, 2013.

VOLÓCHINOV, Valentin. Marxismo e filosofia da linguagem: problemas fundamentais do método sociológico na ciência da linguagem (1929). Tradução Sheila Grillo, Ekaterina Vólkova Américo. São Paulo: Editora 34, 2017.

Recebido em: 9 set. 2020

Aceite em: 16 nov. 2020 